\title{
Realizações do Serviço de Documentação em 1962
}

país conheceu, em 1962, uma fase de acontecimentos politicos e sociais que repercutiram decisivamente na formação do nosso destino histórico como nação independente e progressista

Não obstante algumas oscilações de ordem econômica ou financeira, o cômputo da atividade nacional, nesse periodo de crise de desenvolvimento, manteve-se firme, sem qualquer sintoma alarmante de fraqueza ou exaustão.

A um duvidoso retraimento em uns poucos setores industriais ou comerciais, extremamente sensiveis em swas estruturas superadas, tivemos, em contrapartida, como lucro rendoso a afirmação política de um povo que não se abstém do direito de decidir.

Foi, então, possivel, graças a essa atitude, e amplo diálogo, a que assistimos, entre a Nação e os seus dirigentes, diálogo de que resultou mais invulnerável o princípio da autoridade constiti cional.

Os benefícios dessa atmosfera de confiança e respunsalilidade fizeram -se, descie logo, sentir no âmbito da vida administrativa que prosseguiu em sua expansão normal.

O D.A.S.P. constitui um bom exemplo, nesse sentido. Órgão staff da Presidência da República, pôde, prontamente, atender a tôc as as situações de emergência, com idêntico zêlo e dinamismo. Em nenhum instante viu-se tolhido em iniciativas criadores para disciplinar e comandaz os movimentos de nossa rêde burocrática. Suas múltiplas tarefas procesaram-se em têrmos de apreciáve] produtividade, mantendo, aliás, uma tradição que lhe é peculiar: tradição do trabalho silencioso e austero executado pelos seus órgãos.

Em mais de uma oportunidade o Serviço de Documentação lançou-se à frente, por assim dizer, nessa faina cotidiana. Destinado por natureza a documentar a ação administrativa da Presidência da República, as várias seções que o integram cumpriram, plenamente, as suas finalidades.

Adotando rigoroso critério de etapas, o Serviço de Documentação traçou, vara o ano de 1962, planos todos êles realizados, sem a menor dilação de prazo ou substituição de projetos. 
A Revista do Setviço Público, além de inovações técnicas que lhe emprestam nôvo feitio, passou a circular regularmente, em números trimestrais, restabelecendo a pontualidade indispensável ao seu prestígio de publicação especializada.

Por outro lado, enriquecida de outras seções, projetou com mais fidelidade a experiência e o pensamento brasileiro em matéria de administração pública, através da colaboração de eminentes professôres e técnicos de comprovada competência.

O elevado indice de procura dos seus exemplares, quase sempre esgotados, atesta, de modo inequívoco, o conceito em que a Revista é tida entre os estudiosos e o funcionalismo em geral.

As edições lançadas pelo Serviço de Documentação, no ano recém-findo, foram o resultado também dêsse esquema de planejamento. Houve em tôdas elas o cuidado de divulgar conhecimentos que viessem a contribuir para o aperfeiçoamento profissio. nal ou cultural dos servidores públicos.

Em nenhuma dessas publicações deixará o leitor de colhêr informações úteis e atualizadas, elaboradas em têrmos de absoluta seriedade. São ao todo vinte edições, das quais doze, ainda não lançadas, encontram-se inteiramente entregues ao Departamento de Imprensa Nacional.

O Serviço de Documentação, neste comêço de ano, não alimenta outro propósito senão o de bem servir, como pretende ter servido em 1962. Com mais experiência, espera melhorar ainda mais a sua programação para um público cada vez mais exigente e numeroso.

Estamos certos de que não faltaremos à nossa ambição, tanto mais que com um Poder Executivo mais prestigiado e desembaraçado, a ação administrativa se fará com maior projeção e firmeza.

\section{TRABALHOS EDITADOS EM 1962}

1. A Administração Munzcipal de Guaranésia (Tomo III - A Planificação Municipal) - Autor: A. Delorenzo Neto - Tiragem: 1.500 exemplares.

2. A Missão das Bibliotecas Nacionais - Separata da "Revista do Serviço Público" de abril-maio-junho de 1961 - Tiragem: 1.500 exemplares.

3. Fichas para emp-éstimos de livros na Biblioteca do D.A.S.P. - Tiragem: 10.000 exemplares.

4. História Administrativa do Brasil - Vol. IV - Parte VI - Autor: João Alfredo Libânio Guedes - Tiragem: 5.000 exemplares.

5. Manual de Serviço dos Processos das Pensões Militares - Tiragem: 2.000 exemplares.

6. Português e Redação Oficial - Autor: Vittorio Bergo - Tiragem: 3.000 exemplares. 
7. Prontuário de Redação Oficial - Autor: João Luiz Ney - Tiragem: 5.000 exemplares.

8. Temas de Politica e Filosofia - Autor: Djacir Menezes - Tiragem: 3.000 exemplares.

\section{REVISTA DO SERVIÇO PÜBLICO}

\section{PUBLICAÇÕES EM ANDAMENTO NO DEPARTAMENTO} DE IMPRENSA NACIONAL

$\begin{array}{lll}2^{\circ} & \text { trimestre de } 1961 \text { - Tiragem: } 7.000 \text { exemplares } \\ 3^{\circ} \text { trimestre de } 1961 \text { - Tiragem: } 7.000 \text { exemplares } \\ 4^{\circ} \text { trimestre de } 1961 \text { - Tiragem: } 7.000 \text { exemplares } \\ 1^{\circ} \text { trimestre de } 1962 \text { - Tiragem: } 7.000 \text { exemplares } \\ 2^{\circ} \text { trimestre de } 1962 \text { - Tiragem: } 7.000 \text { exemplares } \\ 3^{\circ} \text { trimestre de } 1962 \text { - Tiragem: } 7.000 \text { exemplares } \\ 4^{\circ} \text { trimestre de } 1962 \text { - Tiragem: } 7.000 \text { exemplares }\end{array}$

1. Aspectos de Relaš̃es Públicas - (Separata da Revista do Serviço Público de abril-maio-junho de 1961 - janeiro-fevereiro-março e outubronovembro-dezembro de 1962) - Autor: Sylla M. Chaves - Tiragem: 1.500 exemplares.

2. Classificação de Cargos (Leg:slação) - Tiragem: 3.000 exemplares.

3. Diretrizes e Bases da Documentação - Tiragem: 2.000 exemplares.

4. Evoluţão das Fronteiras do Brasil até a Proclamação da Independência - Autor: Vera Pasqui Lopes - Tiragem: 1.500 exemplares.

5. História Administrativa do Brasil - Vol. VI - Parte VIII - Autor: Roberto Macedo - Tiragem: 5.000 exemplares.

6. Manual de Serviço dos Processos das Pensões Militares (2" edição) Atualizada - Tiragem: 4.000 exemplares.

7. Marcas de Autor Cuttet-Sanborn ( $2^{*}$ edição) - Autor: Tradução de Silvio do Valle Amaral - Tiragem: 1.000 exemplares.

8. Problemas e Reivindicasões Fundamentais dos Municipios - Tiragem: 2.500 exemplares.

9. Projeto do Estatuto do Trabalhador Rural - Tiragem; 1.500 exemplares.

10. Regimento do D.A.S.P. - 2' edição - Atualizada - Tiragem: 1.000 exemplares.

11. O Regulamento de Acumulação de Cargos - Comentado. - Autor: Corsindio Monteiro da Silva - Tiragem: 3.000 exemplares.

12. Ruy Barbosa - Autor: Alfredo Balthazar da Silveira - Tiragem: 1.500 exemplares.

13. Visconde de Jaguari - Autor: Alfredo Balthazar da Silveira - Tiragem: 1.500 exemplares.

\section{OBRAS ENVIADAS AO DEPARTAMENTO DE IMPRENSA NACIONAL EM' JANEIRO DE 1963}

1. História Administrativa do Brasil - Vol. I - Reedição - Autor: Hêlio Alcântara Avellar e Alfredo D'Escragnolle Taunay - Tiragem: 5.000
exemplares. 
2. História Administrativa do Brasil - Vol. II - Reedição - Autor: Vicente Tapajós - Ti agem: 5.000 exemplares.

3. Histótia Administrativa do Brasil - Vol. VI - Parte VIII - Autor: Roberto Macedo - Tiragem: 5.000 exemplares.

4. D.A.S.P. e sua Legislação - Tiragem: 2.000 exemplares.

5. Ementário de Decisões Administrativas - Vol. 3 - Tiragem: 3.000 exemplares.

6. Catálogo de Publicações do D.A.S.P. - Atualizado - Tiragem: 2.000 exemplares.

7. Atmazéns e Silos (Preservação de grãos alimentícios) - Autor: Eduardo Veiga Soares - Tiragem: 2.000 exemplares.

\section{LANÇAMENTOS PREVISTOS PARA ABRIL DE 1963 ATRAVES DO DEPARTAMENTO DE IMPRENSA NACIONAL}

1. Aspectos de Relaçóes Públicas - (Separata da Revista do Serviço Público de abril-maio-junho de 1961, janeiro-fevereiro-março e outubronovembro-dezembra de 1962) - Autor: Sylla M. Chaves - Tiragem: 1.500 exemplares.

2. Classificicação de Cargos (Legislação) - Tiragem: 3.000 exemplares.

3. Evolução das Fronteiras do Brasil até a Proclamação da Independência - Autor: Vera Pasqui Lopes - Tiragem: 1.500 exemplares.

4. História Administrativa do Brasil - Vol. VI - Parte VIII - Autor: Roberto Maceda - 'Tiragem: 5.000 exemplares.

5. Manual de Serviço dos Processos das Pensões Militares (2 edição) Atualizada - Tiragem: 4.000 exemplares.

6. Projeto do Estatuto to Trabalhador Rural - Tiragem: 1.500 exemplares.

7. Regimento do D.A.S.P. - 20 edição - Atualizada - Tiragem: 1.000 exemplares.

8. O Regulamento de Acumulação de Cargos - Comentado. - Autor: Corsindio Monteiro da Silva - Tiragem: 3.000 exemplares.

\section{Através da Seção de Publicaçóes}

1. Circuíares da Secretaria da Presidência da República, expedidas em 1962 - Tiragem: 1.600 exemplares.

\section{TRABALHOS EXECUTADOS PELA SEÇÃO DE PUBLICAÇÕES}

\section{MIMEÓGRAFO}

\section{Direto:-Geral:}

Formulatório para Requisição de Viaturas ................ 1.000

Formulário Guia de Remessa ....................... 1.000

Serviço de Documentação:

Fichas-papeleta de justificação de faltas .................. 1.500

Recibo de serviça prestado .......................... 1.000

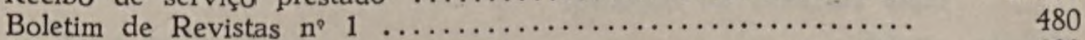

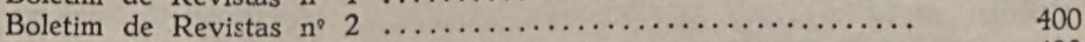

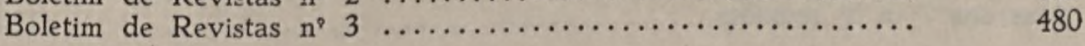




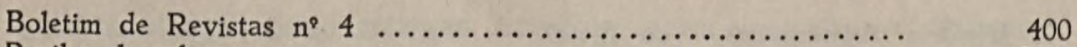

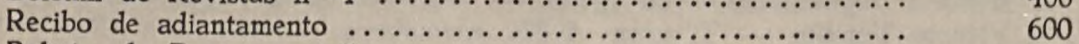

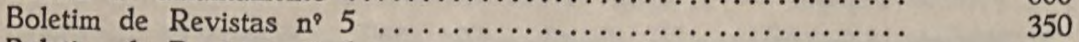

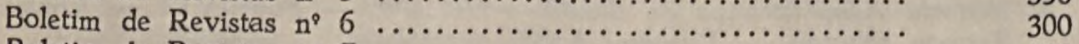

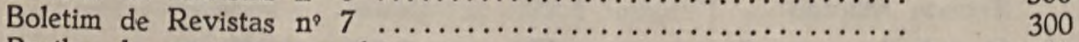

Recibo de serviço prestado .......................... 300

Aviso aos assinantes da R.S.P. ....................... 2.000

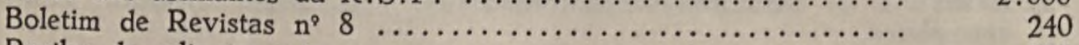

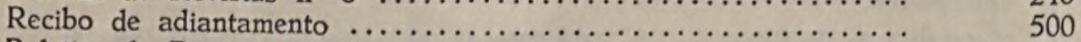

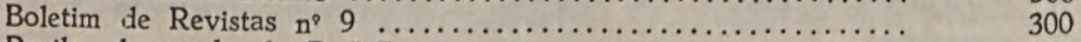

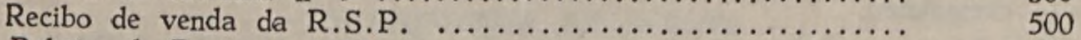

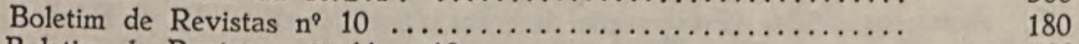

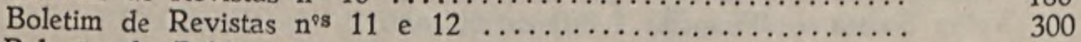

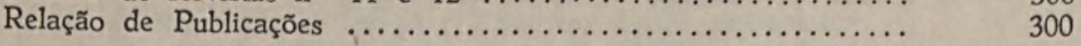

Divisão de Edifícios Públicos:

Fôlha de pagamento a servidor mandado para Brasilia .........

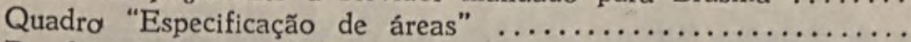

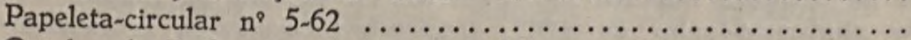

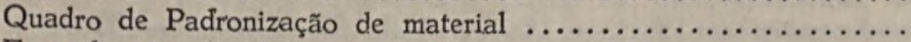

Especificação de Definição de Serviços e Métodos de execução

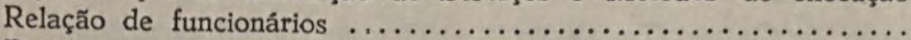

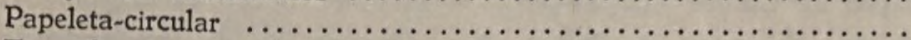

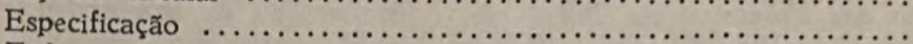

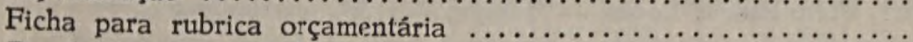

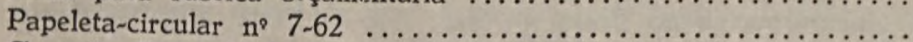

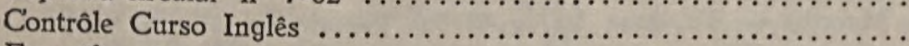

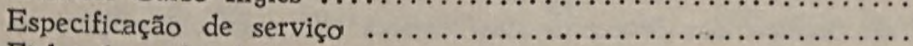

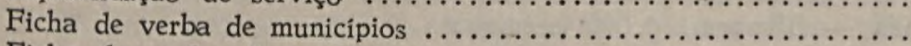

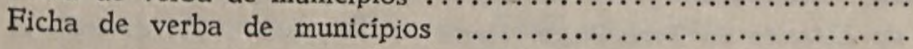

Divisão de Orçamento e Organização:

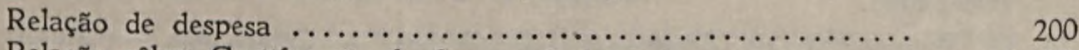

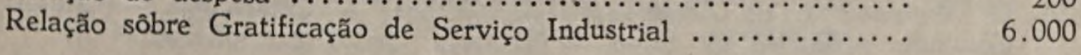

Grupo de Trabalho de Brasilia:

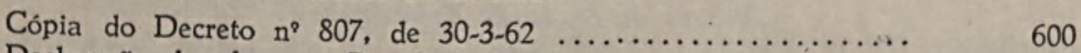

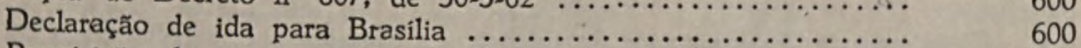

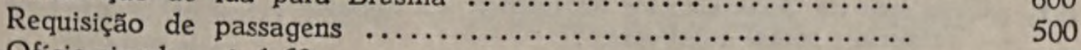

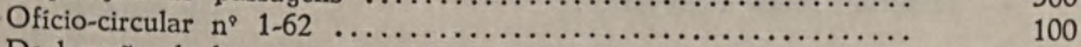

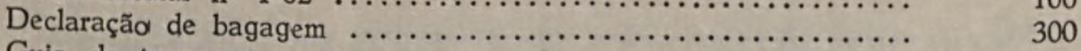

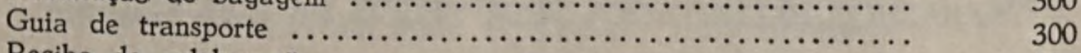

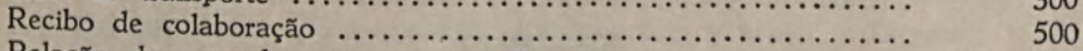

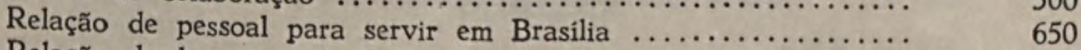

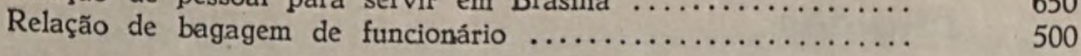

Divisão de Seleção e Aperfeiçoamento:

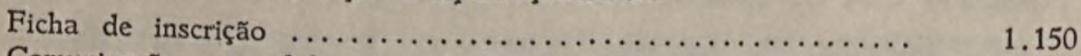

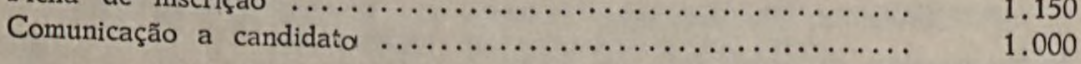

Junta Nacional do Algodão:

Circular $n^{\circ} 62$

Atas das $7^{\circ}$ e $8^{\circ}$ reuniốes 


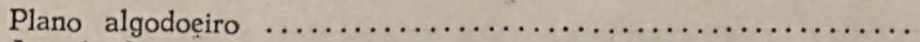

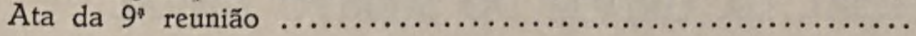

Ministério da Fazenda:

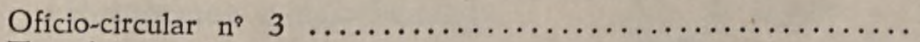

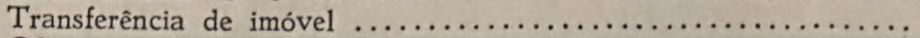

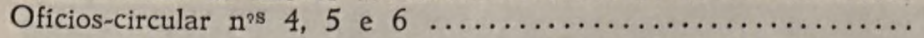

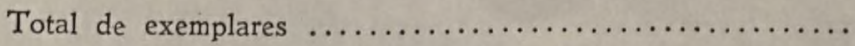

\section{MULTILLITH}

Divisão de Seleção e Ape-feiçoamento:

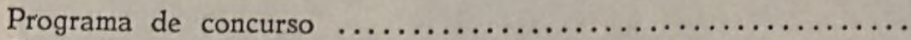

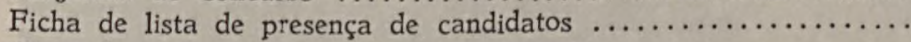

Capa de prova

Serviço de Documentação:

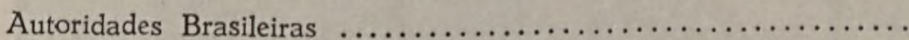

Emendas Constitucionais

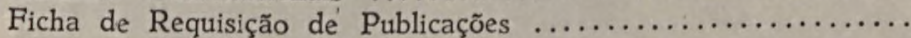

Cartão de cumprimentos

Emendas Constitucionais

Carta para assinatura da R.S.P.

Serviço de Administração:

Boletins de Pessoal n ${ }^{\text {ss }} 694$ a 699

Diretor-Geral:

Cartões-convite para conferência

Cartões de cumprimentos

Total de exemplares

\section{COMPOSIÇÃO TIPOGRÁFICA}

Divisão de Edifícios Públicos:

Cartão-convite ciclo de palestras

Serviço de Documentação:

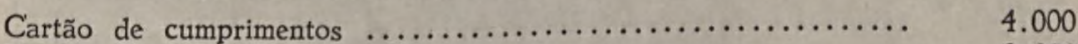

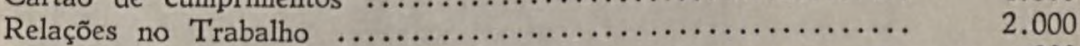

Cartão - Prazo para assinatura ........................ 200

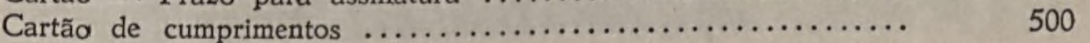

Diretor-Geral:

Cartão de cumprimentos $\ldots \ldots \ldots \ldots \ldots \ldots \ldots \ldots \ldots \ldots \ldots \ldots \ldots \ldots, \quad 100$

Total de exemplares $\ldots \ldots \ldots \ldots \ldots \ldots \ldots \ldots \ldots \ldots \ldots \ldots, \quad 8.200$ 


\section{OFICIAL DA ORDEM DO MÉRITO NAVAL}

O DIRETOR-GERAL DO DASP



Flagrante da solenidade em que o Dr. A. Fonseca Pimentel, Diretor-Geral do DASP, era condecorado Oficial da Ordem do Mérito Naval, em 13 de dezembro de 1692 